\title{
Reflections on the first year of Nature Clinical Practice Nephrology
}

\author{
Suzanne J Farley
}

This month, Nature Clinical Practice Nephrology celebrates its first anniversary. The inaugural issue was published in November 2005, but work began long before then to ensure that the launch of this new journal would be smooth and successful. The crucial initial step was recruitment of our Editor-in-Chief. That a nephrologist of the caliber of Bob Schrier made a commitment to the journal while it was still just a concept was testament to the strength of the editorial model and the reputation of Nature Publishing Group.

Appointment of the in-house editorial staff of Nature Clinical Practice Nephrology, based in London, began in January 2005. Their first task, under the guidance of Dr Schrier, was to recruit an international Advisory Board. We were fortunate to enlist a panel of more than 30 eminent nephrologists, representative of all geographical regions and nephrological subspecialties. Our Advisory Board members are an integral part of editorial workflow. Through regular contact with our editorial staff, they provide suggestions to the Editor-in-Chief for topics to be covered in the journal.

Suggestions from the Advisory Board approved by Dr Schrier formed the basis of our first commissioning drive in early 2005 . As an asyet-unpublished journal, we sensibly expected it to be challenging to get the world's experts to agree to contribute. Happily, we were proved wrong. The positive response to invitations to write for Nature Clinical Practice Nephrology was overwhelming, and we soon had a large pile of manuscripts to plough through.

After a flurry of editing, stringent peer-review, revision, checking and re-checking, the first issue was published on schedule in November 2005. Every subsequent issue has also been published on time, both in print and onlinethanks must go to the copyediting, production, web and administrative support staff in our
... .distributed

to more than

10,000 readers, [the journal] is ....establishing

itself as an

essential

time-saving

resource for

practicing

nephrologists

SJ Farley is Editor

of Nature Clinical

Practice Nephrology.

Competing interests

The author declared she has no competing interests.

www.nature.com/clinicalpractice doi:10.1038/ncpneph0321
London office for this achievement. It's not enough, however, simply to get each monthly issue to the printers. Raising awareness of any new publication is crucial if it is to gain a foothold in an already crowded marketplace, and our sales and marketing teams have done a fantastic job.

Once the monthly routine of getting each installment of Nature Clinical Practice Nephrology to press was established, we turned our attention to capitalizing on early success. Constant innovation and responsiveness to the needs of readers and authors are essential to the ongoing viability of any publication. Feedback from our audience spurred us to launch new initiatives. Advanced online publication —initially of Practice Point articles-will be rolled out in January 2007. Synopses of new guidelines endorsed by the ISN are currently being processed. And the first free online collection of premium nephrology content from across Nature Publishing Group-a 'Web Focus' on secondary hyperparathyroidismwill appear this month.

We are also delighted to announce that, after protracted review by a panel of biomedical experts, Nature Clinical Practice Nephrology has been accepted for indexing in MEDLINE. MEDLINE joins an extensive list of databases that already index the journal, namely EMBASE, ISI Web of Knowledge, Current Contents/ Clinical Medicine, CINAHL, and CAS (Chemical Abstracts Service).

Currently distributed to more than 10,000 readers, and with over 7,000 individuals electing to receive electronic Table of Contents alerts, Nature Clinical Practice Nephrology is well on the road to establishing itself as an essential time-saving resource for practicing nephrologists. We thank all of those involved in the success of the journal to date, and commit ourselves to maintaining the momentum. 